\title{
Quality of life in people living with HIV in Romania and Spain
}

\author{
Meaghan Kall ${ }^{* *} \mathbb{D}$, Ujué Fresán ${ }^{2}$, Danielle Guy ${ }^{3}$, Graham Brown ${ }^{4}$, Cristina Burgui ${ }^{2}$, Jesús Castilla², \\ Victor lonel Grecu ${ }^{5}$, Florentina Dumitrescu ${ }^{5}$, Valerie Delpech ${ }^{1}$ and Jeffrey V. Lazarus ${ }^{3}$
}

\begin{abstract}
Background: Health-related quality of life (HRQoL) is a crucial component in assessing and addressing the unmet needs of people, especially those with chronic illnesses such as HIV. The aim of the study was to examine and compare the health-related quality of life of people living with HIV in Romania and Spain, compared to the general populations of each country.
\end{abstract}

Methods: A cross-sectional survey was conducted among adults ( $\geq 18$ years) attending for HIV care in Romania and Spain from October 2019 to March 2020. The survey included two validated HRQoL instruments: a generic instrument, EQ-5D-5L, and an HIV-specific instrument, PozQoL, and questions on socio-demographics, HIV-related characteristics, physical and mental health conditions, and substance use. Multivariable linear regression was used to determine factors associated with HRQoL.

Results: 570 people living with HIV responded (170 in Romania and 400 in Spain). The median age was 31 (18-67) in Romania and 52 (19-83) in Spain. Anxiety/depression symptoms were frequently reported by people with HIV (Romania: 50\% vs 30\% in the Romanian population; Spain: 38\% vs 15\% in Spanish population). Spain reported higher

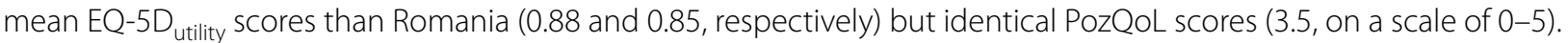
In both countries, health concerns were highlighted as a key issue for people with HIV. In multivariable analysis, two factors were consistently associated with worse HRQoL in people with HIV: bad or very bad self-rated health status and presence of a mental health condition. In Romania, being gay/bisexual and being disabled/unemployed were associated with worse HRQoL. Whereas in Spain, older age and financial insecurity were significant predictors.

Conclusions: Our results indicated a good HRQoL for people living with HIV in Romania and Spain; however, worse HRQoL profiles were characterized by health concerns, poor self-rated health status, and the presence of mental health conditions. This study highlights the importance of monitoring HRQOL in people living with HIV due to the chronic nature of the disease. In this highly-treatment experienced group, disparities were found, particularly highlighting mental health as an area which needs more attention to improve the well-being of people living with HIV.

Keywords: EQ-5D, Chronic diseases, HIV/AIDS, Health-related quality of life, PozQoL, Romania, Spain

*Correspondence: Meaghan.Kall@phe.gov.uk

${ }^{1}$ HIV/STI Department, Public Health England, London NW9 5EQ, UK

Full list of author information is available at the end of the article

\begin{abstract}
Background
Health-related quality of life (HRQoL) is a multidimensional construct that relates one's health to their overall feelings of well-being and perceived ability to function physically, mentally and emotionally [1]. HRQoL is distinguishable from other health metrics in that it is selfreported by the patient and represents an attempt to
\end{abstract}

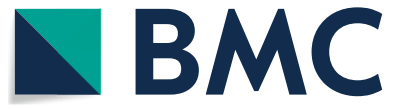

(c) The Author(s) 2021. Open Access This article is licensed under a Creative Commons Attribution 4.0 International License, which permits use, sharing, adaptation, distribution and reproduction in any medium or format, as long as you give appropriate credit to the original author(s) and the source, provide a link to the Creative Commons licence, and indicate if changes were made. The images or other third party material in this article are included in the article's Creative Commons licence, unless indicated otherwise in a credit line to the material. If material is not included in the article's Creative Commons licence and your intended use is not permitted by statutory regulation or exceeds the permitted use, you will need to obtain permission directly from the copyright holder. To view a copy of this licence, visit http://creativecommons.org/licenses/by/4.0/. The Creative Commons Public Domain Dedication waiver (http://creativeco mmons.org/publicdomain/zero/1.0/) applies to the data made available in this article, unless otherwise stated in a credit line to the data. 
consider the impact of health on practical aspects of daily life. As such, measuring HRQoL is a crucial component in assessing and addressing the unmet needs of various populations, especially those with chronic illnesses, such as HIV.

Although people living with HIV (PLHIV) can expect a normal life expectancy through combination antiretroviral therapy (ART) when diagnosed and provided treatment promptly, they continue to face a disproportionate burden of chronic health problems, challenges of lifelong treatment and associated side-effects as well as psychological challenges including stigma and discrimination [2, 3]. Previous studies have typically shown lower HRQoL scores among people with HIV compared to the general population, and disparities in HRQoL scores between HIV sub-populations [4-7].

HRQoL data can be used to identify disparities between different populations and help to inform interventions that will ensure long-term retention in care, ART adherence and maintenance of good health [8]. Recently, there have been calls to formally consider good HRQoL as part of the "fourth 90" for people with HIV alongside the UNAIDS 90-90-90 targets to monitor the health system response to HIV [9].

This has led to greater interest in quantifying and measuring HRQoL among people with HIV; however, there is no agreed consensus on what tool is best to measure it [10]. The challenge is for HRQoL scales to be short and simple while also being sensitive enough to capture patients' experience. There are a wide variety of HRQoL scales available, both generic and HIV-specific. Generic HRQoL scales apply to the general population and may not have been validated for use in HIV populations. EurQoL (EQ-5D) is a 5-item scale that has been widely used among general populations around the world and specifically among people living with HIV [11]. HIV-specific HRQoL scales include PROQOL-HIV [12], WHOQOLHIV-BREF [13] and MOS-HIV [14]. However, the number of items in these scales range from 31 to 43 questions, making them burdensome for routine data collection at the clinic or population levels. The PozQoL scale is a new HIV-specific HRQoL instrument with 13 items, with promise for regular use in healthcare settings [15].

In this study, we assess the health-related quality of life of PLHIV in Romania and Spain, two European countries with contrasting epidemics: Romania with a younger (median age 33) population in eastern Europe and Spain with an ageing (median age 49) HIV population in western Europe. We use two brief, validated HRQoL instruments: a widely-used generic instrument, EQ5D-5L (5-items), and an HIV-specific tool, PozQoL (13items). We describe the distribution of EQ-5D domains among people living with HIV compared to the general population in both countries, and determine factors associated with a lower HRQoL.

This study is part of the European Commission's Joint Action on Integration of Testing and Linkage to Care for HIV, viral hepatitis, tuberculosis, and sexual transmitted infections in Europe (INTEGRATE) [16].

\section{Methods}

Infectious disease hospitals with HIV cohorts in Romania and Spain were identified through the INTEGRATE joint action [16]. The hospitals were self-selected after expressing interest in collecting data on HRQoL, but they also represented contrasting epidemic and therefore good comparators for using two different HRQoL instruments. A cross-sectional study was conducted among adult ( $\geq 18$ years) PLHIV in Romania and Spain from October 2019 to March 2020. A structured questionnaire was developed by an expert advisory group of clinicians, social scientists, and PLHIV. The questionnaire was initially written in English and translated to Romanian and Spanish. Quality checks were performed through backtranslation and piloting of the questionnaire in each language ( $n=3-5$ local volunteers) to ensure content validity and comprehension. Those patients unable to complete the questionnaire due to language or literacy were not eligible.

\section{Population and setting Romania}

The survey was conducted at the HIV Department of the "Victor Babes" Clinical Hospital of Infectious Diseases and Pneumophtisiology Craiova, which specializes in treating patients with infectious diseases. It serves a population of around 1.3 million and has an HIV outpatient clinic of 650 patients. HIV patients attend the clinic monthly to collect their prescription ART from the Hospital's HIV Department. They are evaluated clinically every three to six months. Consecutive HIV patients attending the clinic to collect their prescription during the study period were invited to complete the survey.

\section{Spain}

The survey was conducted at the Complejo Hospitalario de Navarra, Pamplona, and Hospital Reina Sofia, Tudela, located in Navarra, an autonomous community in northern Spain. Access to the Spanish healthcare system is universal. HIV care is provided within infectious diseases units located in outpatient clinics. ART is dispensed without charge in hospital pharmacies by specialized personnel.

HIV patients attend the HIV clinic for routine checkups every six months. Consecutive HIV patients 
attending the clinic during the study period were invited to participate.

\section{Measurement and evaluation of HRQoL}

Two instruments were used to assess HRQoL: EQ-5D and PozQoL.

EQ-5D is a simple, generic 5-item instrument for measuring HRQoL and widely used in both clinical and observational studies [17-19]. Although not tailored for PLHIV, it has been used previously to measure HRQoL in this population [20]. The EQ-5D consists of five questions on mobility, self-care, usual activity, pain/discomfort, and anxiety/depression. Each question has five possible answer options, ranging from "no problems at all" to "severe problems" from which a single summary index can be derived, also known as a utility score. This ranges from 0 (representing a state worse than death) to 1 (representing perfect health).

PozQoL is a 13-item instrument designed specifically to measure HRQoL in PLHIV [15]. The instrument groups questions into four subscales covering: health concerns, psychological, social, and functional, which align with the World Health Organizations' conceptualization of QoL [21]. Each question has five possible answer options, ranging from "not at all" to "extremely". Scores range from 1 (low QoL) to 5 (very high QoL). In addition to its construct validity and reliability, the brevity of the tool makes it easier to administer than other HIV-specific instruments [15].

The two primary outcomes in this study were the EQ-5D utility score and the summary averaged PozQoL score.

The independent variables included demographic and socioeconomic factors: age, gender, sexual orientation, educational attainment, employment status, housing stability (stable housing defined as owning or renting and unstable housing defined as temporary accommodation, living with family or friends, or homeless), and having enough money for basic needs (always or not always). Ethnicity was collected in Romania and migrant status was collected in Spain after consultation with local teams to select the most culturally appropriate question. HIV-related characteristics included year of diagnosis, ART status, and adherence to ART. Health-related behaviours included self-rated health, diagnosed co-morbid physical mental health conditions, polypharmacy (use of five or more medications, including ART [22]), binge drinking (six or more drinks at one time for a woman or eight or more drinks at one time for a man [23]), smoking, and injecting drug use.

\section{Statistical analyses}

The EQ-5D $\mathrm{D}_{\text {utility }}$ score for Spain was constructed using the Hernandez et al. (2018) value set for Spain [24]. The utility score for Romania was constructed using the EuroQol cross-walk UK value set (in the absence of a national value set for Romania [25]). Distribution of EQ-5D domains were compared with population norms in Spain using the Hernandez dataset (2018) [24] and in Romania using the Paveliu et al. (2019) preliminary dataset [26] Records missing data on one or more of the five domains were excluded (Romania $\mathrm{n}=0$ and Spain $\mathrm{n}=18$ ).

PozQoL scores were computed as averages to retain records with missing values ( $0 \%$ of Romanian responses were missing $\geq 1$ item and $18 \%$ of Spanish responses were missing $\geq 1$ item). After recoding negatively worded items, the items within the same sub-scales were averaged together, per the scoring guide [27]. A total score was then created as an average of the completed questions. Participants with $>1$ item missing on any one sub-scale excluded from the analysis (Spain $\mathrm{n}=25(6 \%)$ ) and in Romania no participants had missing data. Score thresholds were set based on the PozQoL validation study for the full scale and sub-scales to assign participants as having very high, high, moderate, or low quality of life. The averaged summary score ranged from 0 to 5 .

We initially performed descriptive analysis of the EQ-5D and PozQoL profile of respondents for each country. The overall EQ-5D utility score of PLHIV in both countries was compared to that of the respective general populations [28].

Both outcomes were treated as continuous and examined separately for each country. Exploratory analysis of EQ-5D utility score and PozQoL score using histograms found they were left skewed, particularly EQ-5D, which had a strong ceiling effect with $43 \%$ of all respondents reporting perfect health. Shapiro-Wilk and D'AgostinoPearson tests confirmed both outcome variables were non-normally distributed ( $<0.0001$ for both). For this reason, inferential analysis was performed using generalized linear modelling, with a $\gamma$ distribution and log link. Univariable analysis was performed against each of the independent variables. Step-wise multiple linear regression was used to determine factors associated with poor HRQoL. Variables included in the final model included age and sex (a priori due to known associations with HRQoL) and those which were significant at the 0.10 level in the univariable analysis. In this analysis, negative effect estimates indicate worse health whereas positive values indicate better health.

A sensitivity analysis was performed for the EQ-5D utility score to test for variations caused by the ceiling effect. A logistic regression model was fitted with the EQ-5D utility score collapsed into a dichotomous variable 
representing perfect health (yes $=1$ or no $<1$ ). The model also found mental health a strong predictor but could not model self-rated health due to data loss. The main difference using logistic regression was age, which was no longer significant $(p=0.326)$. Given the similarity of the results, the linear model was retained to retain maximum data in the model while noting this difference.

All analyses were conducted using Stata version 15 (Stata Corp, College Station, Texas, USA).

\section{Results}

\section{Descriptive statistics}

We surveyed 170 PLHIV in Romania and 400 PLHIV in Spain (Table 1). The profile of respondents in Romania and Spain was very different. In Romania, the median age was 31 (range 18-67) compared to 52 (19-83) in Spain. In Spain, two-thirds (67\%) were men, compared to less than half $(44 \%)$ in Romania. Only $14 \%$ of respondents were in employment (full-time or part-time) in Romania compared to $60 \%$ of respondents in Spain. Most (86\%) of the Spanish respondents had stable housing situations compared to $60 \%$ in Romania. Financial insecurity was commonly reported, with $38 \%$ of respondents in Romania and 53\% in Spain saying they did not always have enough money to meet their basic needs. Nearly all respondents were on ART (99\% in Romania and 99\% in Spain; adherence was 86\% in Romania and 99\% in Spain.

\section{EQ-5D score, distribution and general population comparisons}

One a scale of 0 to 1 , the mean EQ-5D $\mathrm{D}_{\text {utility }}$ score among people with HIV in Spain was $0.88(\mathrm{SD}=0.16)$ compared to $0.91(\mathrm{SD} \pm 0.15)$ in the general population. In Romania, the mean EQ- $5 \mathrm{D}_{\text {utility }}$ score among people with HIV was $0.85(\mathrm{SD} \pm 0.16)$.

Figure 1 shows the distribution of the EQ-5D domains in Spain and Romania. In both countries, the most affected domain was anxiety/depression (Spain: 38\% reported some problems vs $15 \%$ in general Spanish population; Romania: $50 \%$ reported some problems vs $30 \%$ in the general Romanian population).

Across the other EQ-5D domains, such as pain/discomfort and mobility, PLHIV in Spain reported more problems compared to the general population, whereas PLHIV in Romania reported fewer problems overall.

\section{PozQoL score, distribution and general population comparisons}

Figure 2 shows the distribution of the summary averaged PozQoL scores for each country. In Spain, the summary average PozQoL score was $3.5(\mathrm{SD} \pm 0.71)$ with a range of 1.4 to 5.0 (median 3.6 IQR (3.1-4.0). In Romania, the summary averaged PozQoL score was $3.50 \pm 0.79$ with a range of 1.4-5.0 (median 3.5 IQR (3.0-4.2). In both countries, the lowest summary averaged score was given for the health concerns sub-scale (2.9 in Spain and 3.2 in Romania).

PozQoL scores, overall and for each sub-scale were classified into 'very high,' 'high', 'moderate', and 'low' quality of life using the pre-defined cut-off values from the PozQoL protocol (Fig. 3). In Spain, 58.2\% had 'high' or 'very high QoL', compared to $48.8 \%$ in Romania. In Spain, the PozQoL health concerns sub-scale was most affected, with 1 in 4 (26.7\%) PLHIV scoring in the 'low' QoL category. Women scored worse on the PozQoL psychological and functional sub-scales, and younger adults (aged 18-30 years) scored worse on PozQoL health concerns subscale.

In Romania, the PozQoL functional sub-scale was most affected, with $42 \%$ of respondents scoring in the 'low' QoL category. In both Spain and Romania, the PozQoL social subscale was least affected with only $9 \%$ scoring in the 'low' QoL category.

\section{Factors associated with worse HRQoL in people living with HIV}

In univariable analysis of the EQ-5D scale, several factors were significantly associated with a lower mean EQ$5 \mathrm{D}_{\text {utility }}$ score (Table 1). However, in the adjusted model for Spain only poor self-rated health, older age, and having ever been diagnosed with a mental health condition were predictive of a lower EQ-5D $\mathrm{D}_{\text {utility }}$ score (Table 2).

Likewise, in Romania, several factors were statistically significant in univariable analysis of the EQ- $5 \mathrm{D}_{\text {utility }}$ score, including alcohol and injecting drug use. However, in the fully adjusted model only poor self-rated heath and presence of a diagnosed co-morbid physical health condition were predictive of worse HRQoL. In contrast to Spain, in Romania, mental health conditions and older age were not significantly associated with a lower mean EQ-5D $\mathrm{D}_{\text {util- }}$ ity score in univariable or multivariable analysis.

In the analysis of the summary averaged PozQoL score, four factors were consistently associated with lower scores across most PozQoL sub-scales and in both countries in univariable analysis: gay/bisexual sexual orientation, not having money for basic needs, poor self-rated health, and having ever been diagnosed with a mental health condition (Table 3, results of PozQoL sub-scales in Appendices Tables 4, 5).

In the fully adjusted model of the summary averaged PozQoL score, in Spain, poor self-rated health, ever diagnosed with a mental health condition, and not having money for basic needs were significantly associated with lower PozQoL scores, whereas in Romania a different set of factors emerged: gay/bisexual sexual orientation, employment status (specifically those classed 


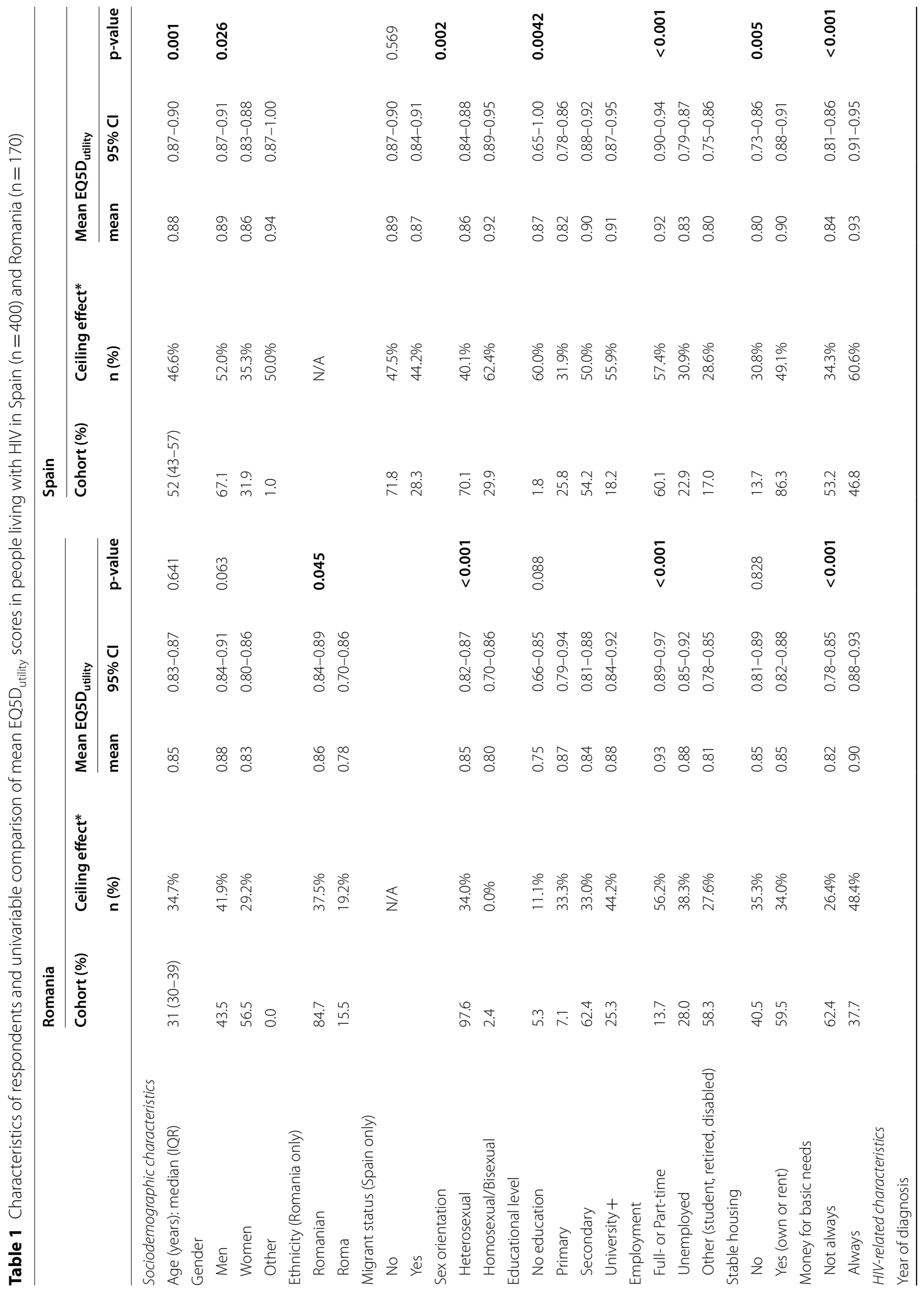




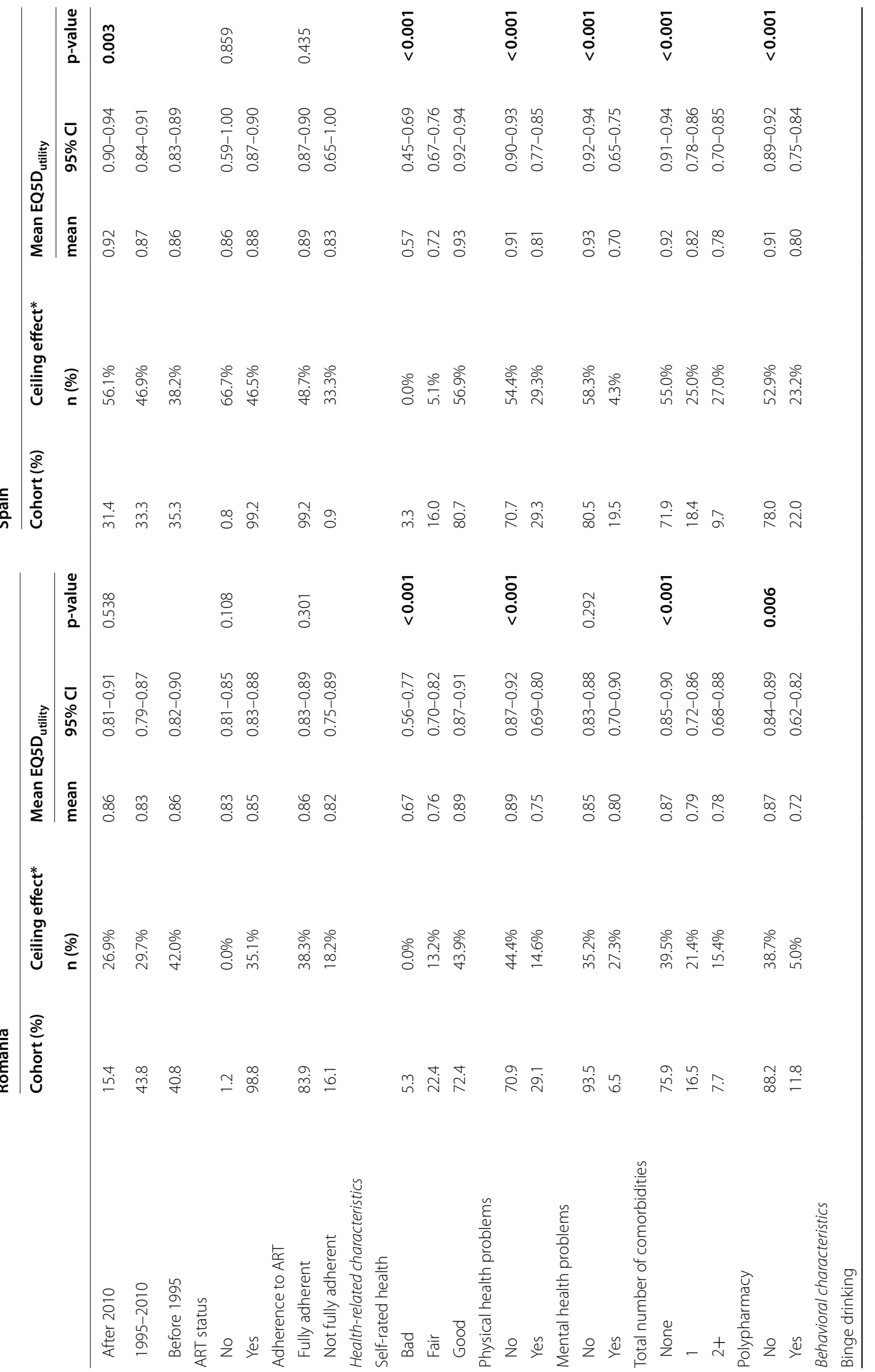




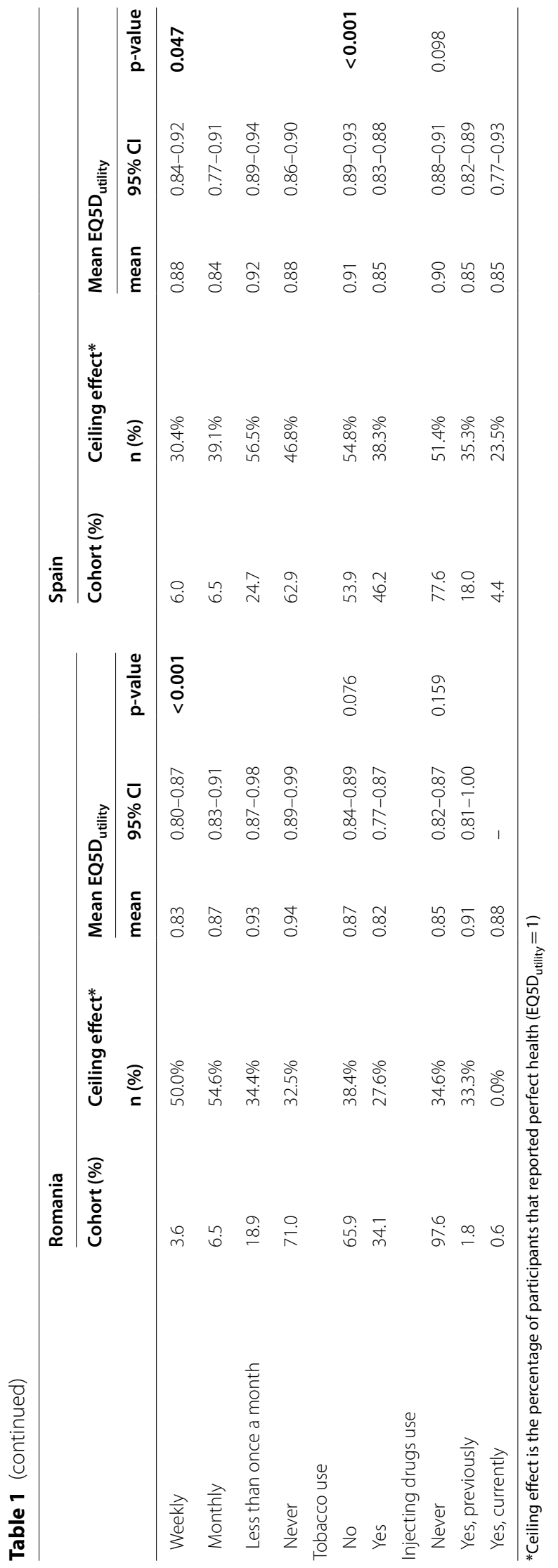




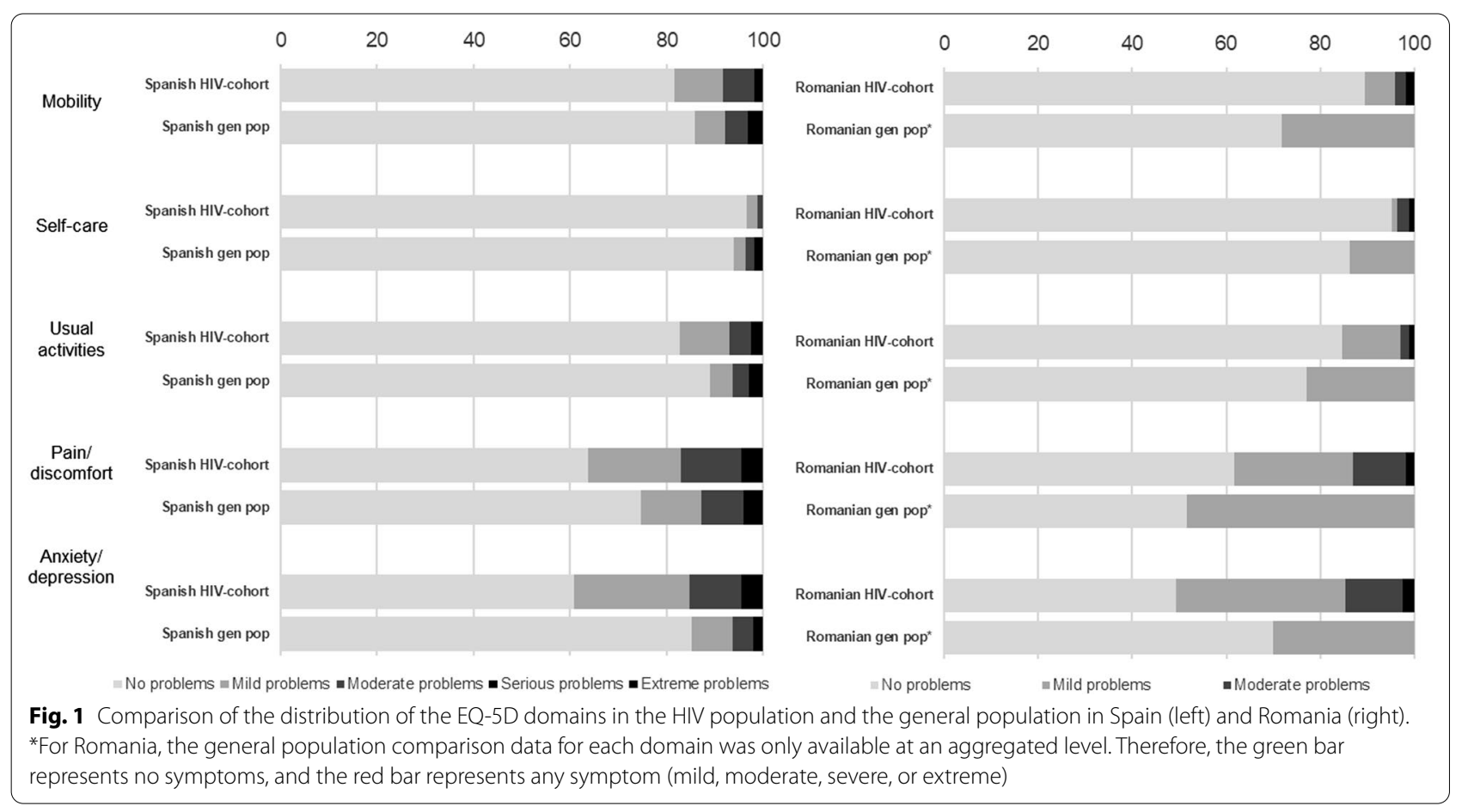

as disabled), and presence of a mental health condition were significantly associated with lower PozQoL scores (Table 2). No factors related to clinical HIV infection, such as ART status and adherence and time since HIV diagnosis, were associated with worse HRQoL by either the EQ-5D or PozQoL measure.

Only explanatory variables with statistically significant results are shown in Table 2. The Romania EQ-5D model was adjusted for age, Roma ethnicity, gender, education, employment, money for basic needs, mental health diagnosis, binge drinking, and ever injecting drug use. The Spain EQ-5D model was adjusted for gender, education, employment, month for basic needs, physical comorbidity, polypharmacy, smoking, and ever injecting drug use. The Romania PozQoL model was adjusted for age, Roma ethnicity, gender, employment, money for basic needs, self-rated health, mental health diagnoses, physical comorbidity and polypharmacy. The Spain PozQoL model was adjusted for age, migrant status, gender, and employment.

\section{Discussion}

This cross-sectional study examined HRQoL in PLHIV in Romania and Spain in 2019-2020. The results suggest that HRQoL for people living with HIV is slightly lower than the general population but statistically comparable. Overall, PLHIV in Romania reported lower EQ-5D utility scores compared to Spain but provided identical PozQoL scores overall. Importantly, these results showed that HRQoL between countries differ, highlighting the importance of having country-specific measurements of HRQoL rather than assuming similar scores for persons with HIV living in different countries.

In this sample of PLHIV with nearly all (>98\%) respondents on ART, no HIV clinical factors were found to be associated with poor HRQoL. This is a positive reflection of the incredible advances in HIV treatment globally as well as the quality of the HIV care provision in both countries health systems. Detailed analysis of the HRQoL of people either not taking or non-adherent to ART was therefore limited by small numbers.

Psychological issues, poor health status, and having concerns about one's health were found to be important predictors of poor HRQoL. This aligns with previous research which has found PLHIV disproportionately experience poorer mental health [29], caused by factors such as coping with a recent HIV diagnosis, the impact of a diagnosis on relationships, stigmatisation and experiences of discrimination, social isolation and loneliness, and the experience of living with a chronic illness $[7,30,31]$. Additionally, marginalized populations who are also at risk of HIV such as gay and bisexual populations, migrants, drug users, and prisoners also experience poorer mental health [32].

Our study found that social and structural factors, such as sexuality, financial instability and employment, were important predictors of HRQoL, particularly in Romania. This reflects the cultural and societal differences between 


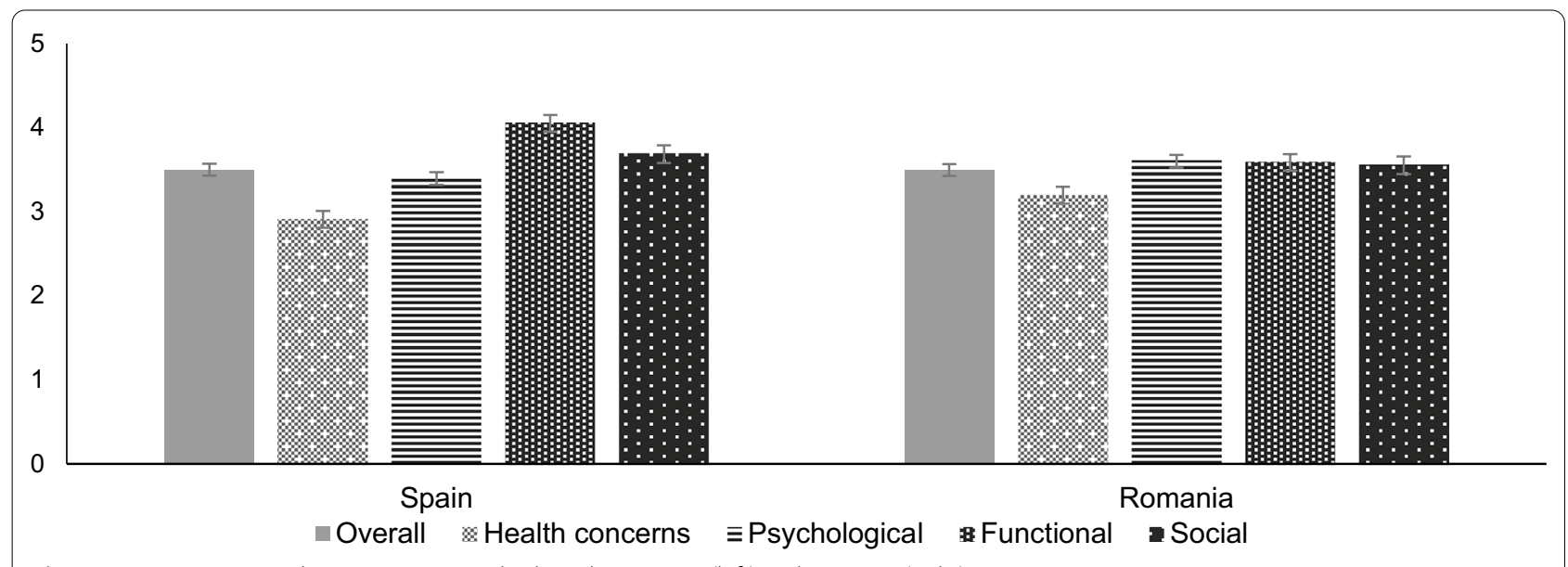

Fig. 2 Summary averaged PozQoL scores and sub-scales in Spain (left) and Romania (right)

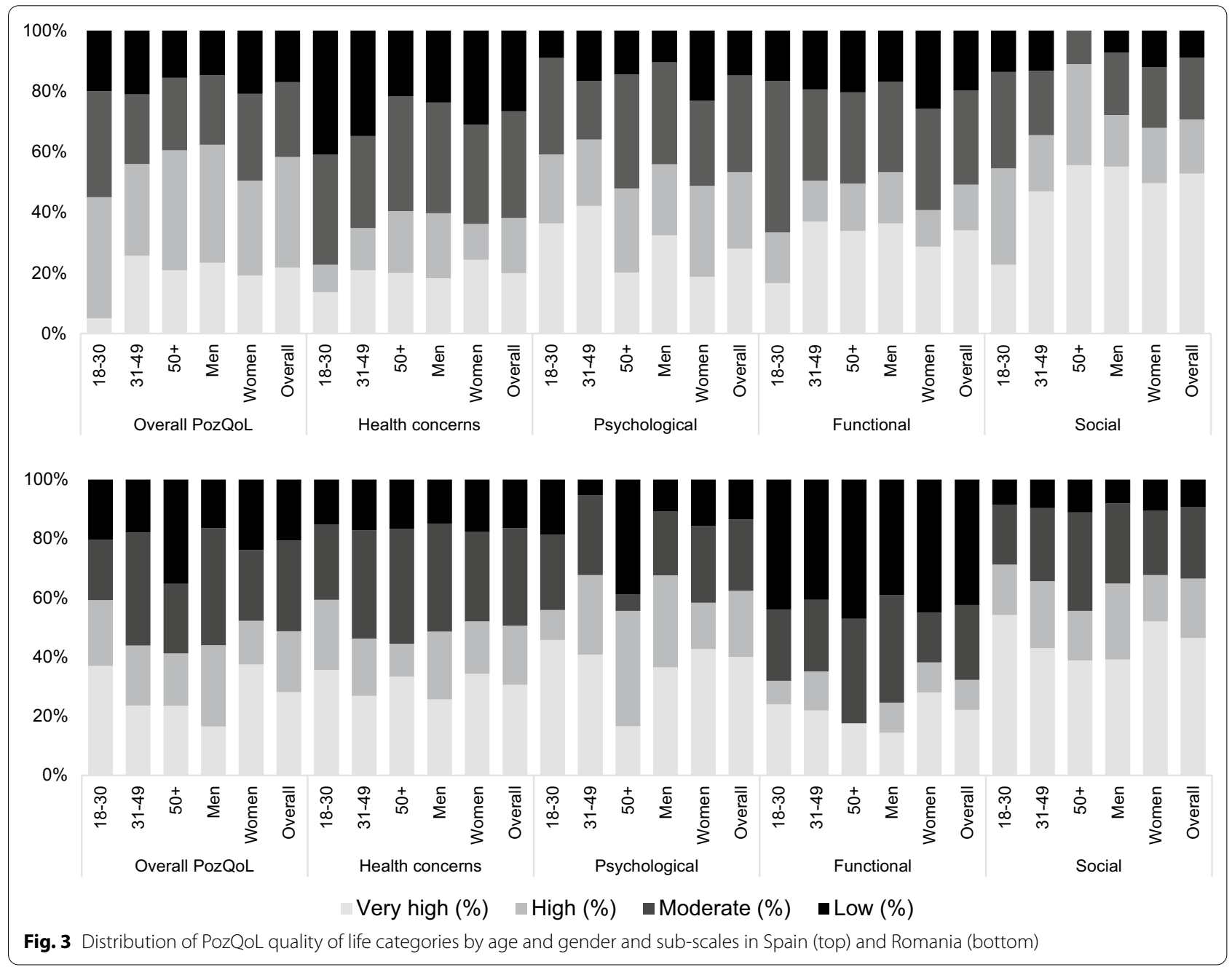


Table 3 Characteristics of respondents and univariable comparison of mean PozQoL scores in people living with HIV in Spain $(\mathrm{n}=400)$ and Romania $(\mathrm{n}=170)$

\begin{tabular}{|c|c|c|c|c|c|c|}
\hline & \multicolumn{3}{|c|}{ Romania } & \multicolumn{3}{|l|}{ Spain } \\
\hline & \multicolumn{3}{|c|}{ PozQoL mean score } & \multicolumn{3}{|c|}{ PozQoL mean score } \\
\hline & Mean & $95 \% \mathrm{Cl}$ & p value & Mean & $95 \% \mathrm{Cl}$ & $\mathrm{p}$ value \\
\hline \multicolumn{7}{|l|}{ Sociodemographic characteristics } \\
\hline Age (years): median (IQR) & 3.50 & $3.38-3.62$ & 0.531 & 3.50 & $3.43-3.57$ & 0.037 \\
\hline \multicolumn{7}{|l|}{ Gender } \\
\hline Men & 3.48 & $3.33-3.63$ & 0.772 & 3.57 & $3.48-3.65$ & 0.0195 \\
\hline Women & 3.51 & $3.33-3.69$ & & 3.38 & $3.24-3.51$ & \\
\hline Other & & & & 2.82 & $1.42-4.22$ & \\
\hline \multicolumn{7}{|l|}{ Ethnicity (Romania only) } \\
\hline Romanian & 3.57 & $3.44-3.70$ & 0.002 & & & \\
\hline Roma & 3.10 & $2.84-3.36$ & & & & \\
\hline \multicolumn{7}{|l|}{ Migrant status (Spain only) } \\
\hline Born in Spain & & & & 3.56 & $3.48-3.64$ & 0.0117 \\
\hline Born abroad & & & & 3.35 & $3.20-3.50$ & \\
\hline \multicolumn{7}{|l|}{ Sex orientation } \\
\hline Heterosexual & 3.50 & $3.38-3.63$ & $<0.001$ & 3.47 & $3.38-3.53$ & 0.423 \\
\hline Homosexual/Bisexual & 2.95 & $2.53-3.36$ & & 3.53 & $3.41-3.66$ & \\
\hline \multicolumn{7}{|l|}{ Educational level } \\
\hline No education & 3.06 & $2.54-3.58$ & 0.193 & 3.04 & $2.18-3.90$ & 0.1372 \\
\hline Primary & 3.28 & $2.80-3.76$ & & 3.41 & $3.25-3.57$ & \\
\hline Secondary & 3.50 & $3.36-3.64$ & & 3.53 & $3.43-3.63$ & \\
\hline University + & 3.65 & $3.38-3.92$ & & 3.60 & $3.46-3.75$ & \\
\hline \multicolumn{7}{|l|}{ Employment } \\
\hline Full- or Part-time & 3.86 & $3.58-4.15$ & $<0.001$ & 3.58 & $3.49-3.67$ & 0.0131 \\
\hline Unemployed & 3.69 & $3.51-3.87$ & & 3.27 & $3.09-3.45$ & \\
\hline Other (student, retired, disabled) & 3.30 & $3.13-3.46$ & & 3.47 & $3.29-3.65$ & \\
\hline \multicolumn{7}{|l|}{ Stable housing } \\
\hline No & 3.52 & $3.33-3.71$ & 0.744 & 3.41 & $3.21-3.61$ & 0.349 \\
\hline Yes (own or rent) & 3.48 & $3.32-3.64$ & & 3.51 & $3.44-3.59$ & \\
\hline \multicolumn{7}{|l|}{ Money for basic needs } \\
\hline Not always & 3.38 & $3.23-3.53$ & 0.010 & 3.29 & $3.18-3.40$ & 0.0000 \\
\hline Always & 3.69 & $3.50-3.88$ & & 3.73 & $3.64-3.81$ & \\
\hline \multicolumn{7}{|l|}{ HIV-related characteristics } \\
\hline \multicolumn{7}{|l|}{ Year of diagnosis } \\
\hline After 2010 & 3.39 & $3.09-3.69$ & 0.456 & 3.47 & $3.34-3.61$ & 0.474 \\
\hline 1995-2010 & 3.46 & $3.26-3.66$ & & 3.45 & $3.31-3.60$ & \\
\hline Before 1995 & 3.58 & $3.41-3.75$ & & 3.56 & $3.44-3.68$ & \\
\hline \multicolumn{7}{|l|}{ ART status } \\
\hline No & 3.15 & $2.70-3.61$ & 0.570 & 2.90 & $1.46-4.33$ & 0.045 \\
\hline Yes & 3.50 & $3.38-3.62$ & & 3.50 & $4.43-3.57$ & \\
\hline \multicolumn{7}{|l|}{ Adherence to ART } \\
\hline Fully adherent & 3.52 & $3.37-3.67$ & 0.738 & 3.55 & $3.47-3.62$ & 0.446 \\
\hline Not fully adherent & 3.58 & $3.26-3.90$ & & 3.26 & $1.33-5.18$ & \\
\hline \multicolumn{7}{|l|}{ Health-related characteristics } \\
\hline \multicolumn{7}{|l|}{ Self-rated health } \\
\hline Bad & 3.07 & $2.70-3.44$ & $<0.001$ & 2.82 & $2.25-3.39$ & $<0.001$ \\
\hline Fair & 3.15 & $2.91-3.39$ & & 3.09 & $2.90-3.27$ & \\
\hline Good & 3.63 & $3.50-3.77$ & & 3.61 & $3.53-3.68$ & \\
\hline
\end{tabular}


Table 3 (continued)

\begin{tabular}{|c|c|c|c|c|c|c|}
\hline & \multicolumn{3}{|c|}{ Romania } & \multicolumn{3}{|l|}{ Spain } \\
\hline & \multicolumn{3}{|c|}{ PozQoL mean score } & \multicolumn{3}{|c|}{ PozQoL mean score } \\
\hline & Mean & $95 \% \mathrm{Cl}$ & $p$ value & Mean & $95 \% \mathrm{Cl}$ & $p$ value \\
\hline \multicolumn{7}{|l|}{ Physical health problems } \\
\hline No & 3.61 & $3.47-3.74$ & 0.015 & 3.57 & $3.48-3.65$ & 0.019 \\
\hline Yes & 3.25 & $3.00-3.50$ & & 3.36 & $3.22-3.51$ & \\
\hline \multicolumn{7}{|l|}{ Mental health problems } \\
\hline No & 3.54 & $3.42-3.66$ & 0.019 & 3.65 & $3.58-3.73$ & $<0.001$ \\
\hline Yes & 2.86 & $2.33-3.39$ & & 3.03 & $2.86-3.20$ & \\
\hline \multicolumn{7}{|c|}{ Total number of comorbidities } \\
\hline None & 3.56 & $3.43-3.69$ & 0.500 & 3.57 & $3.48-3.66$ & 0.1427 \\
\hline 1 & 3.36 & $3.00-3.71$ & & 3.47 & $3.29-3.66$ & \\
\hline $2+$ & 3.29 & $2.83-3.76$ & & 3.36 & $3.03-3.70$ & \\
\hline \multicolumn{7}{|l|}{ Polypharmacy } \\
\hline No & 3.55 & $3.42-3.67$ & 0.039 & 3.53 & $3.44-3.61$ & 0.093 \\
\hline Yes & 3.12 & $2.74-3.50$ & & 3.38 & $3.24-3.53$ & \\
\hline \multicolumn{7}{|l|}{ Behavioral characteristics } \\
\hline \multicolumn{7}{|l|}{ Binge drinking } \\
\hline Weekly & 3.51 & $3.36-3.66$ & 0.303 & 3.45 & $3.15-3.76$ & 0.3978 \\
\hline Monthly & 3.52 & $3.25-3.79$ & & 3.38 & $3.09-3.66$ & \\
\hline Less than once a month & 3.17 & $2.81-3.54$ & & 3.60 & $3.46-3.75$ & \\
\hline Never & 3.54 & $3.44-3.64$ & & 3.49 & $3.40-3.58$ & \\
\hline \multicolumn{7}{|l|}{ Tobacco use } \\
\hline No & 3.55 & $3.40-3.70$ & 0.193 & 3.53 & $3.43-3.62$ & 0.504 \\
\hline Yes & 3.39 & $3.20-3.58$ & & 3.48 & $3.37-3.59$ & \\
\hline \multicolumn{7}{|l|}{ Injecting drugs use } \\
\hline Never & 3.48 & $3.36-3.60$ & $<0.001$ & 3.50 & $3.41-3.58$ & 0.069 \\
\hline Yes, previously & 4.41 & $4.10-4.72$ & & 3.62 & $3.47-3.78$ & \\
\hline Yes, currently & 3.46 & - & & 3.24 & $2.91-3.58$ & \\
\hline
\end{tabular}

to ensure patients remain engaged in long-term care. As part of this project, a parallel HRQoL survey was piloted in people undergoing treatment for hepatitis $C$ infection. This survey experienced challenges in recruitment. In contrast to HIV, hepatitis $C$ is curable and with widespread access to direct-acting antivirals in Europe. However, the pool of eligible participants became too small to recruit a sample large enough for meaningful comparison. HRQoL surveys are likely to be more feasible in HIV populations who attend healthcare services at regular intervals. Additional research is needed to understand whether HRQoL surveys can be feasibly applied in other infectious disease populations.

\section{Conclusion}

This study highlights the importance of understanding HRQoL in people living with HIV through the use of two HRQoL assessment tools. EQ-5D scores indicated a disproportionate burden of mental health symptoms impacting quality of life in people living with HIV, while the PozQoL scores indicated that concerns about future health are prevalent. Poor self-rated health was a good predictor of poor quality of life overall and may be considered as a screening tool for additional interventions to assess the holistic needs of people living with HIV.

\section{Appendix 1}

See Table 4.

\section{Appendix 2}

See Table 5. 


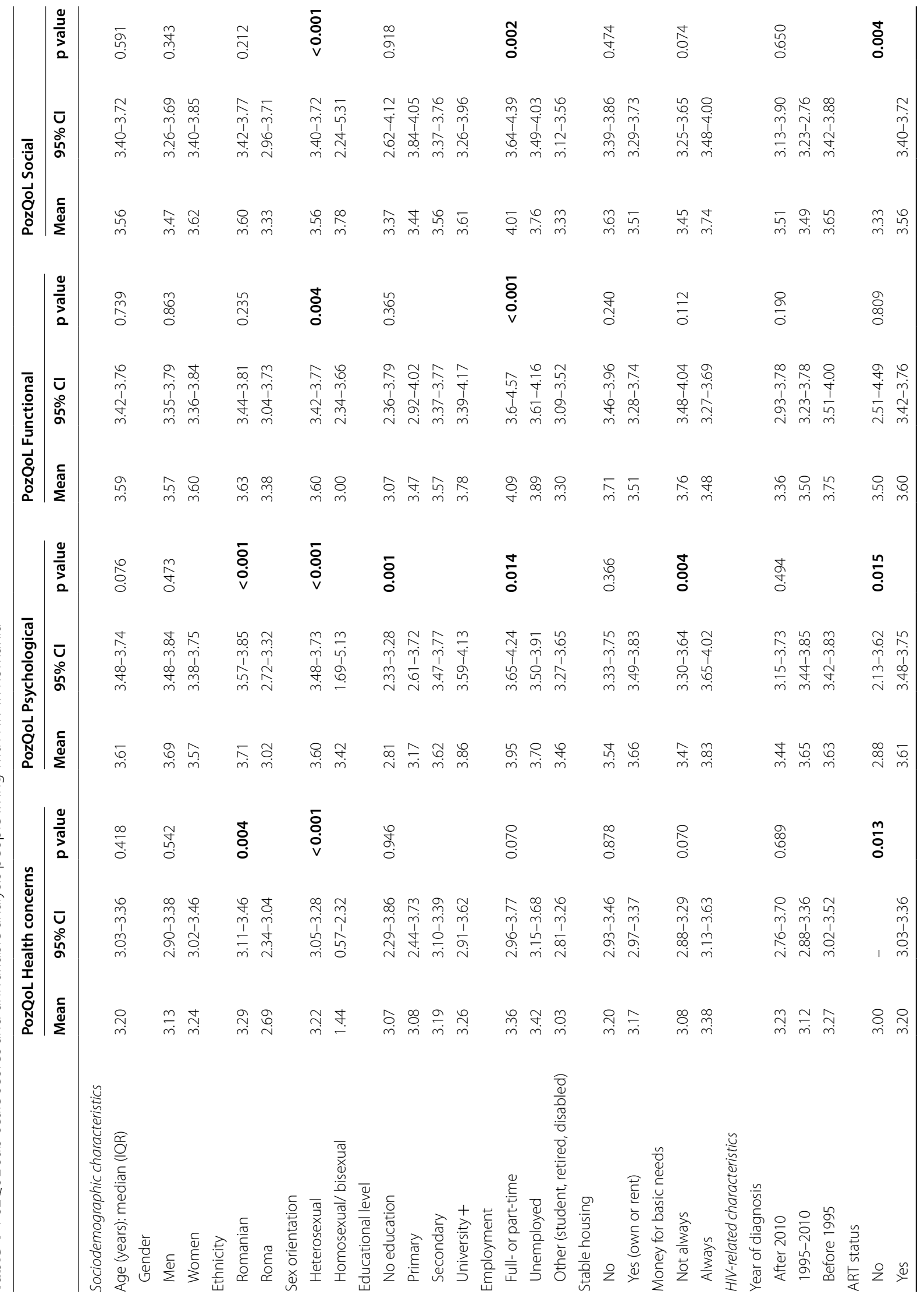




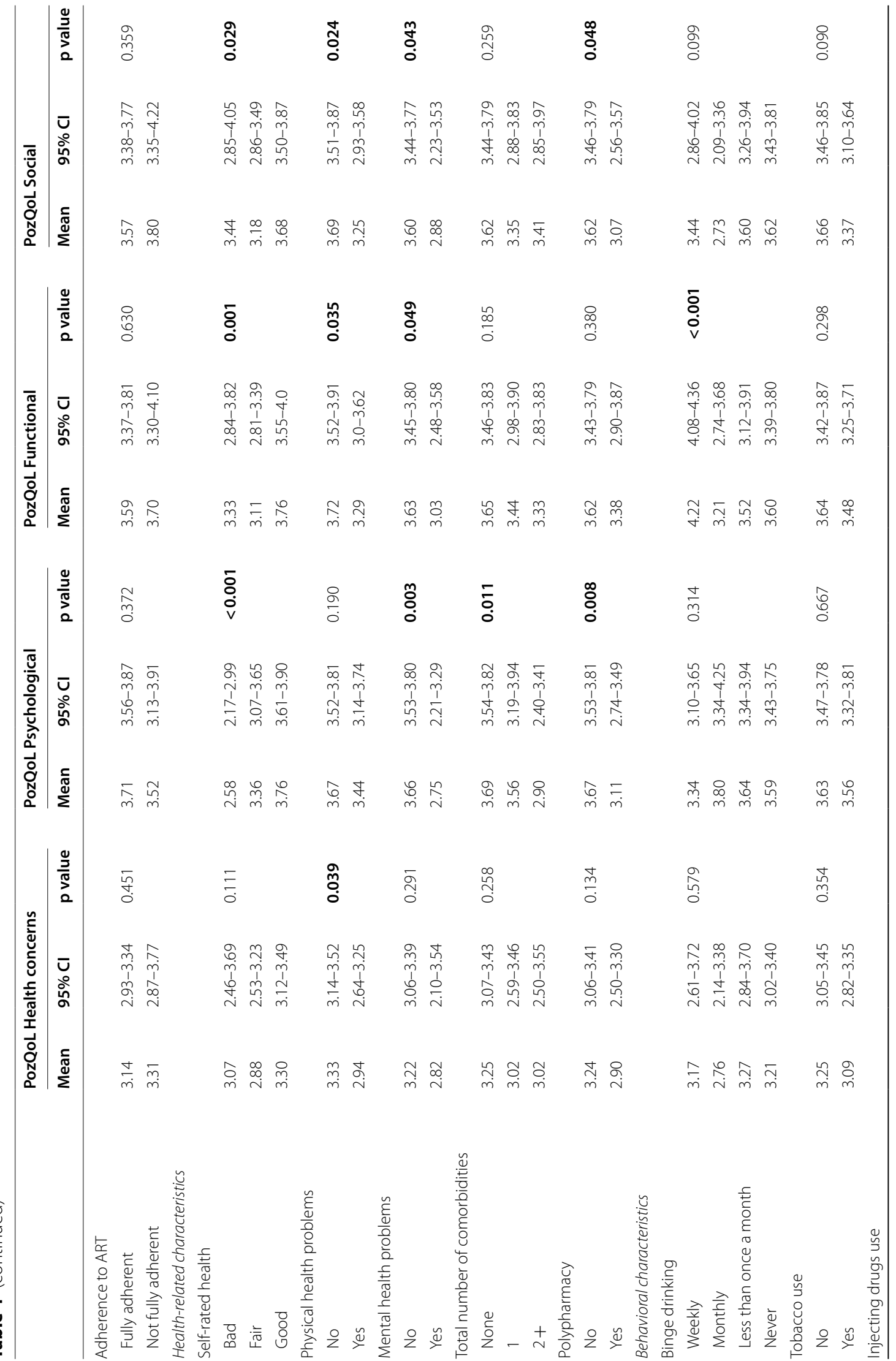




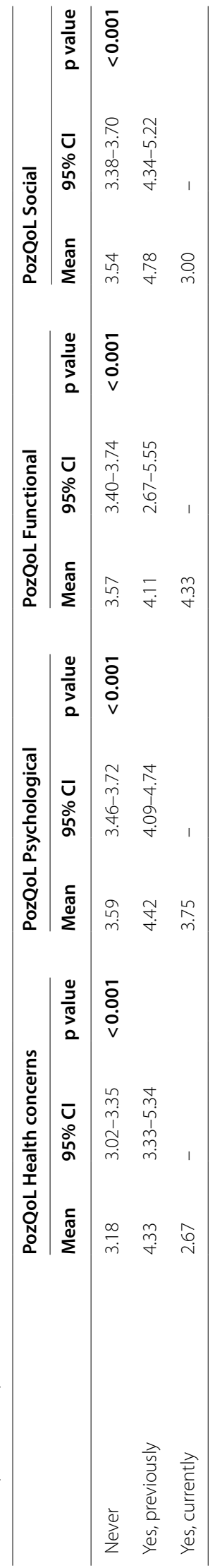




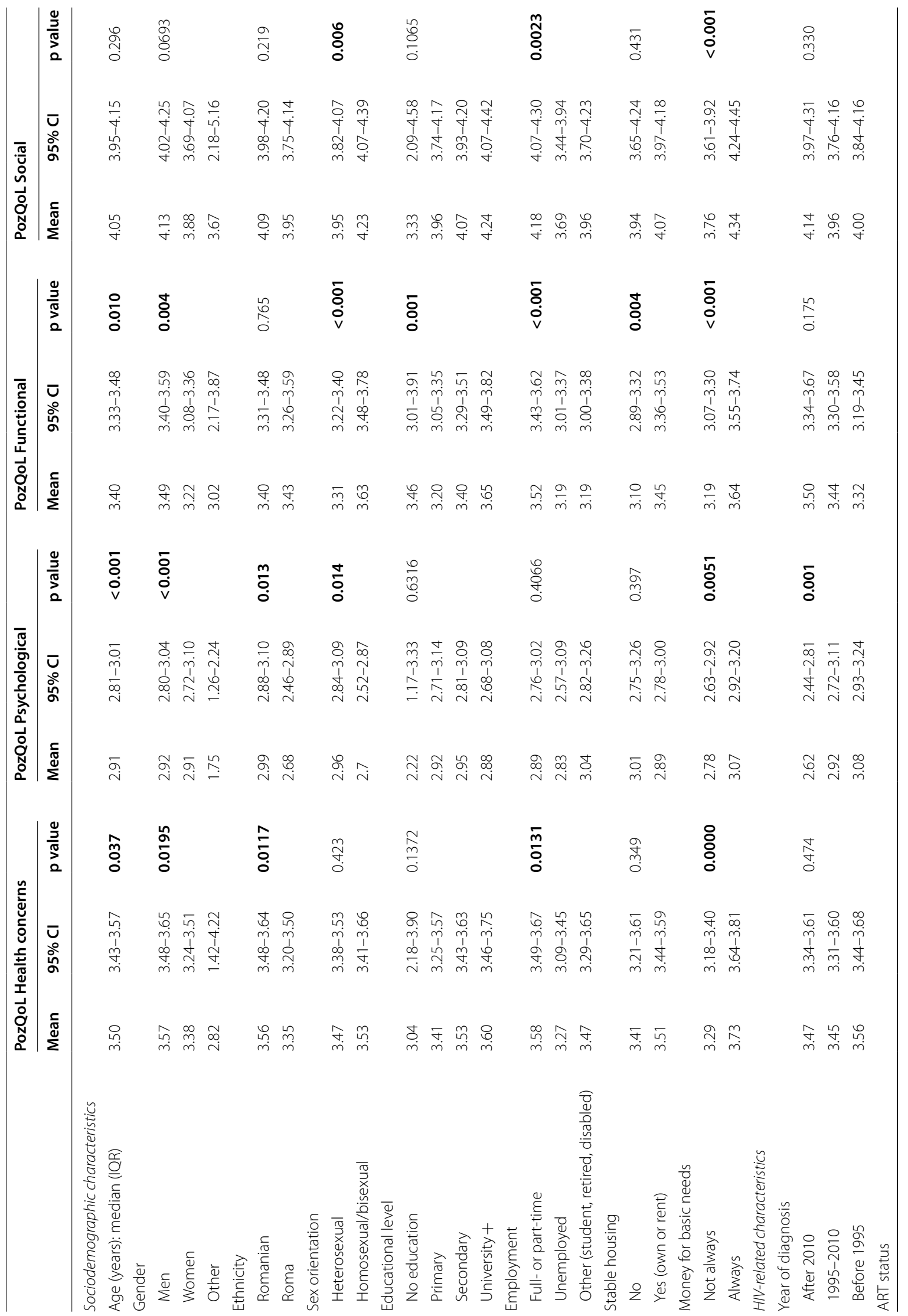




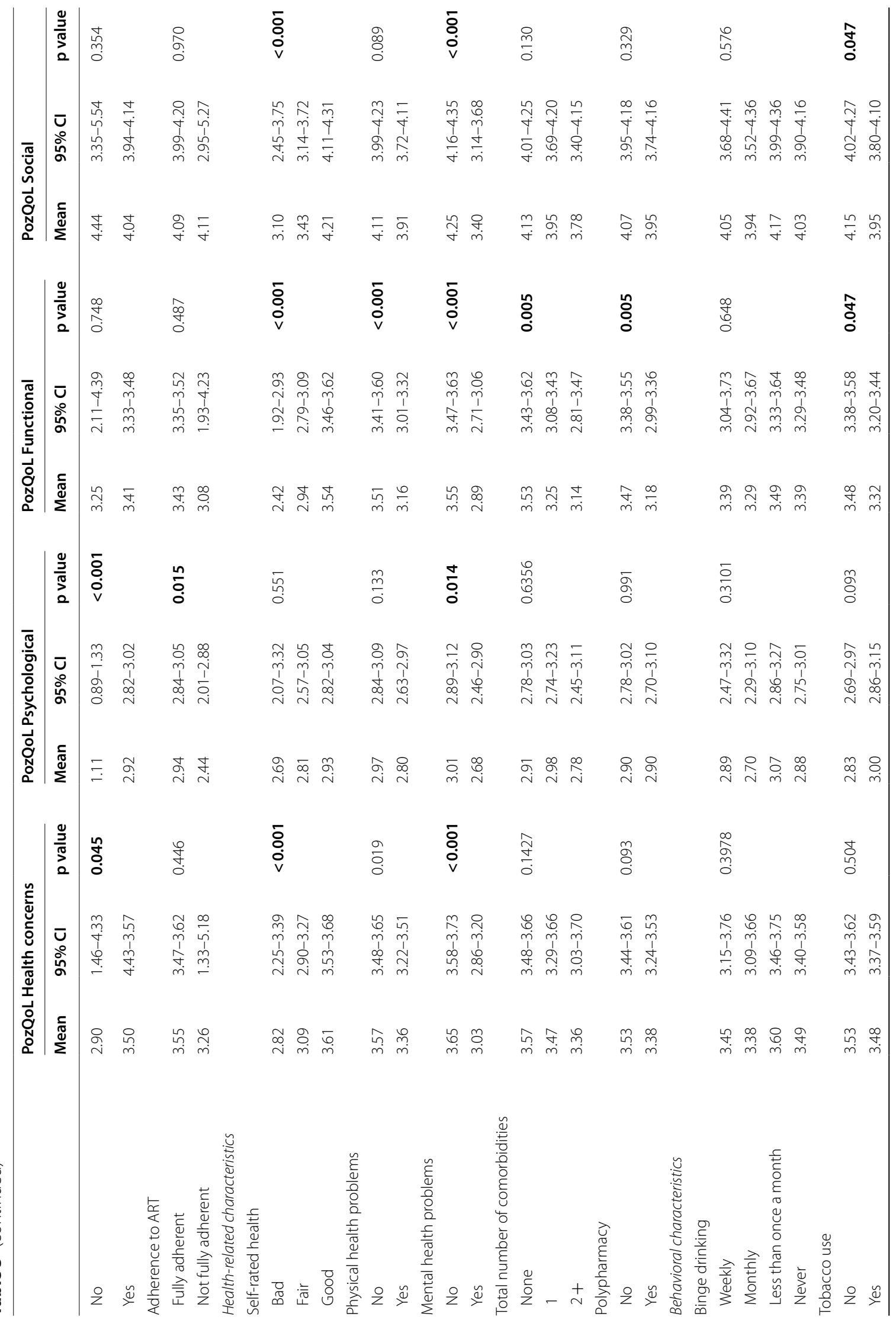




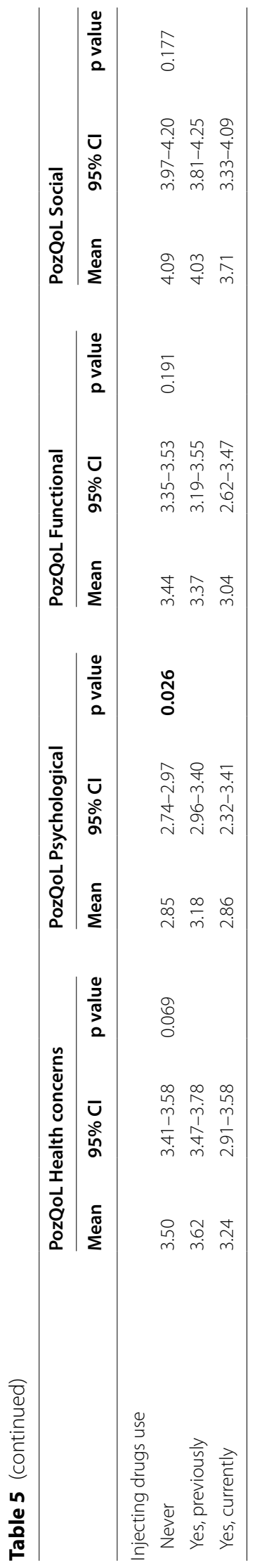




\section{Abbreviations}

ART: Antiretroviral therapy; EQ-5D: EurQoL five dimensions questionnaire; HRQoL: Health-related quality of life; PLHIV: People living with HIV; UK: United Kingdom; HIV: Human Immunodeficiency virus; QoL: Quality of Life; INTEGRATE: The European Commission's Joint Action on Integration of Testing and Linkage to Care for HIV, viral hepatitis, tuberculosis, and sexual transmitted infections in Europe.

\section{Acknowledgements}

JVL is supported by a Spanish Ministry of Science, Innovation and Universities Miguel Servet grant (Instituto de Salud Carlos III/ESF, European Union [CP18/00074]) and with DG further acknowledges support to ISGlobal from the Spanish Ministry of Science, Innovation and Universities through the "Centro de Excelencia Severo Ochoa 2019-2023" Programme (CEX2018-000806-S), and from the Government of Catalonia through the CERCA Programme."

\section{Authors' contributions}

$\mathrm{JVL}$ and MK conceived of the study and developed the protocol. Data collection was done by CB and UFS in Spain and VIG and FD in Romania. MK, UFS, and DG analyzed and interpreted the survey data. DG, MK, and JVL drafted the manuscript. All authors reviewed, read and approved the final manuscript.

\section{About this supplement}

This article has been published as part of BMC Infectious Diseases Volume 21, Supplement 2 2021: Results from INTEGRATE - the EU Joint Action on integrating prevention, testing and linkage to care strategies across HIV, viral hepatitis, TB and STIs in Europe. The full contents of the supplement are available at https://bmcinfectdis.biomedcentral.com/articles/supplements/volume-21supplement-2.

\section{Funding}

The INTEGRATE Joint Action was co-funded by the 3rd Health Programme of the European Union under 215 grant agreement no 761319

\section{Declarations}

\section{Ethics approval and consent to participate}

The study was approved by the Ethics Commission of the "Victor Babes" Clinical Hospital of Infectious Diseases and Pneumophtisiology in Craiova, Romania and the Navarra Ethical Committee for Clinical Research in Spain in 2019. Written informed consent was obtained from all participants.

\section{Consent for publication}

Not applicable

\section{Competing interests}

The authors declare that they have no competing interests.

\section{Author details}

${ }^{1}$ HIV/STI Department, Public Health England, London NW9 5EQ, UK. ${ }^{2}$ Instituto de Salud Pública de Navarra-IdiSNA-CIBERESP, Pamplona, Spain. ${ }^{3}$ Barcelona Institute for Global Health (ISGlobal), Hospital Clínic, University of Barcelona, S08036 Barcelona, Spain. ${ }^{4}$ Centre for Social Impact, University of New South Wales, High Street, Sydney, Australia. ${ }^{5}$ Spitalul Clinic de Boli Infectioase si Pneumoftiziologie "Victor Babes" Craiova, 200515 Craiova, Romania.

\section{Received: 9 August 2021 Accepted: 12 August 2021}

Published: 14 September 2021

\section{References}

1. Clayson DJ, Wild DJ, Quarterman P, Duprat-Lomon I, Kubin M, Coons SJ. A comparative review of health-related quality-of-life measures for use in HIV/AIDS clinical trials. Pharmacoeconomics. 2006;24:751-65.

2. Lowther K, Selman L, Harding R, Higginson IJ. Experience of persistent psychological symptoms and perceived stigma among people with HIV on antiretroviral therapy (ART): a systematic review. Int J Nurs Stud. 2014;51:1171-89.
3. Safreed-Harmon K, Anderson J, Azzopardi-Muscat N, Behrens GMN, d'Arminio Monforte A, Davidovich U, et al. Reorienting health systems to care for people with HIV beyond viral suppression. Lancet HIV. 2019;6:e869-77.

4. Miners A, Phillips A, Kreif N, Rodger A, Speakman A, Fisher M, et al. Health-related quality-of-life of people with HIV in the era of combination antiretroviral treatment: a cross-sectional comparison with the general population. Lancet HIV. 2014;1 (1):e32-40.

5. Kall M, Auzenbergs M, Kelly C, Delpech V. Positive voices: the national survey of people living with HIV findings from the 2017 survey. London; 2020. https://assets.publishing.service.gov.uk/government/uploads/ system/uploads/attachment_data/file/857922/PHE_positive_voices_ report_2019.pdf. Accessed 2 Sept 2020.

6. Hikasa S, Shimabukuro S, Hideta K, Kuroda N, Higasa S, Sawada A, et al. Quality of life of people living with HIV compared with that of the general population in Japan. J Infect Chemother. 2017;23(10):698-702.

7. Engelhard EAN, Smit C, Van Dijk PR, Kuijper TM, Wermeling PR, Weel AE, et al. Health-related quality of life of people with HIV: an assessment of patient related factors and comparison with other chronic diseases. AIDS. 2018:32(1):103-12.

8. Kall M, Marcellin F, Harding R, Lazarus JV, Carrieri P. Patient-reported outcomes to enhance person-centred HIV care. Lancet HIV. 2020;7:e59-68.

9. Lazarus JV, Safreed-Harmon K, Barton SE, Costagliola D, Dedes N, del Amo VJ, et al. Beyond viral suppression of HIV - the new quality of life frontier. BMC Med. 2016;14:94

10. Cooper V, Clatworthy J, Harding R, Whetham J, Brown A, Leon A, et al. Measuring quality of life among people living with HIV: a systematic review of reviews. Health Qual Life Outcomes. 2017. https://doi.org/10. 1186/s12955-017-0778-6.

11. EuroQol Research Foundation. EQ-5D; 2020. https://euroqol.org/. Accessed 2 Sep 2020

12. Duracinsky M, Herrmann S, Berzins B, Armstrong AR, Kohli R, Le Coeur $\mathrm{S}$, et al. The development of PROQOL-HIV. JAIDS J Acquir Immune Defic Syndr. 2012;59(5):498-505.

13. O'Connell KA, Skevington SM. An international quality of life instrument to assess wellbeing in adults who are HIV-positive: a short form of the WHOQOL-HIV (31 items). AIDS Behav. 2012;16(2):452-60.

14. Wu AW, Revicki DA, Jacobson D, Malitz FE. Evidence for reliability, validity and usefulness of the Medical Outcomes Study HIV Health Survey (MOSHIV). Qual Life Res 1997:481-93.

15. Brown G, Mikołajczak G, Lyons A, Power J, Drummond F, Cogle A, et al. Development and validation of PozQoL: a scale to assess quality of life of PLHIV. BMC Public Health. 2018;18(1):527.

16. The INTEGRATE Consortium. About JA; 2017. https://integrateja.eu/conte nt/about-ja. Accessed 2 Sep 2020

17. Lloyd A, Pickard AS. The EQ-5D and the EuroQol Group. Value Health. 2019:22:21-2.

18. Devlin NJ, Brooks R. EQ-5D and the EuroQol group: past, present and future. Appl Health Econ Health Policy. 2017;15:127-37.

19. EuroQol Research Foundation. EQ-5D-5L; 2020. https://euroqol.org/eq5d-instruments/eq-5d-5l-about/. Accessed 2 Sep 2020

20. Wu AW, Hanson KA, Harding G, Haider S, Tawadrous M, Khachatryan A, et al. Responsiveness of the MOS-HIV and EQ-5D in HIV-infected adults receiving antiretroviral therapies. Health Qual Life Outcomes. 2013;11:42.

21. World Health Organization. WHOQOL: measuring quality of life. WHO World Health Organization; 2014. https://www.who.int/healthinfo/ survey/whoqol-qualityoflife/en/. Accessed 2 Sep 2020.

22. Back D, Marzolini C. The challenge of HIV treatment in an era of polypharmacy. J Int AIDS Soc. 2020. https://doi.org/10.1002/jia2.25449.

23. National Health Service. Binge drinking. NHS; 2019. https://www.nhs.uk/ live-well/alcohol-support/binge-drinking-effects/. Accessed 2 Sep 2020.

24. Hernandez G, Garin O, Pardo Y, Vilagut G, Pont À, Suárez M, et al. Validity of the EQ-5D-5L and reference norms for the Spanish population. Qual Life Res. 2018;27(9):2337-48.

25. EuroQol Research Foundation. EQ-5D-5L valuation crosswalk index value calculator; 2020. https://euroqol.org/eq-5d-instruments/eq-5d-51about/valuation-standard-value-sets/crosswalk-index-value-calculator/. Accessed 2 Sep 2020

26. Paveliu MS, Olariu E, Caplescu R, Oluboyede Y, Niculescu-Aron IG, Finch $A P$, et al. Health-related quality of life in Romania: cross-sectional studies using EQ-5D-3L and EQ-5D-5L. Value Heal. 2019;22:S829-30. 
27. Australian Research Centre in Sex H and S. PozQoL scale implementation kit; 2019. https://pozqolhome.files.wordpress.com/2019/09/pozqol-imple mentation-kit-june-2018-revsept2019.pdf. Accessed 2 Sep 2020.

28. Ministerio de Sanidad SS e I. Encuesta Nacional de Salud. España 2011/12 Calidad de vida relacionada con la salud en adultos: EQ-5D-5L. Madrid; 2014

29. Carey MP, Carey KB, Maisto SA, Schroder KEE, Vanable PA, Gordon CM. HIV risk behavior among psychiatric outpatients: association with psychiatric disorder, substance use disorder, and gender. J Nerv Ment Dis. 2004;192(4):289-96

30. Rueda S, Mitra S, Chen S, Gogolishvili D, Globerman J, Chambers L, et al. Examining the associations between HIV-related stigma and health outcomes in people living with HIV/AIDS: a series of meta-analyses. BMJ Open. 2016;6(7): e011453.

31. Lampe F, Miners A, Krief N, Miltz A, Phillips A, et al. Comparison of depression and anxiety between HIV-positive and HIV-negative people. In: 22nd International AIDS Conference. TUPEB079. Amsterdam, Netherlands; 2018.

32. Chander G, Himelhoch S, Moore RD. Substance abuse and psychiatric disorders in HIV-positive patients: epidemiology and impact on antiretroviral therapy. Drugs. 2006;66:769-89.

33. Gulácsi L, Rotar AM, Niewada M, Löblová O, Rencz F, Petrova G, et al. Health technology assessment in Poland, the Czech Republic, Hungary, Romania and Bulgaria. Eur J Health Econ. 2014. https://doi.org/10.1007/ s10198-014-0590-8.
34. De Smedt D, Clays E, Höfer S, Oldridge N, Kotseva K, Pietro MA, et al. Validity and reliability of the HeartQoL questionnaire in a large sample of stable coronary patients: The EUROASPIRE IV Study of the European Society of Cardiology. Eur J Prev Cardiol. 2015;23(7):714-21.

35. Rencz F, Gulácsi L, Drummond M, Golicki D, Prevolnik Rupel V, Simon J, et al. EQ-5D in Central and Eastern Europe: 2000-2015. Qual Life Res. 2016;25(11):2693-710.

36. Olariu E, Paveliu MS, Baican E, Oluboyede Y, Vale L, Niculescu-Aron IG. Measuring health-related quality of life in the general population and Roma communities in Romania: Study protocol for two cross-sectional studies. BMJ Open. 2019. https://doi.org/10.1136/bmjopen-2019-029067.

37. Uniunea Nationala a Organizatiilor Persoanelor Afectate de HIV/SIDA. Evoluția HIV/SIDA în România; 2019. https://unopa.ro/evolutia-hiv-sidain-Romania-31-decembrie-2019/. Accessed 14 Sep 2020.

38. Unidad de Vigilancia de VIH y Comportamientos de Riesgo. Vigilancia Epidemiológica del VIH y sida en España 2018: Sistema de Información sobre Nuevos Diagnósticos de VIH y Registro Nacional de Casos de Sida. Plan Nacional sobre el Sida/Centro Nacional de Epidemiología-ISCIII. Madrid; Nov 2019.

\section{Publisher's Note}

Springer Nature remains neutral with regard to jurisdictional claims in published maps and institutional affiliations.
Ready to submit your research? Choose BMC and benefit from:

- fast, convenient online submission

- thorough peer review by experienced researchers in your field

- rapid publication on acceptance

- support for research data, including large and complex data types

- gold Open Access which fosters wider collaboration and increased citations

- maximum visibility for your research: over 100M website views per year

At BMC, research is always in progress.

Learn more biomedcentral.com/submissions 